\title{
EGU2020-11993
}

https://doi.org/10.5194/egusphere-egu2020-11993

EGU General Assembly 2020

(c) Author(s) 2020. This work is distributed under

the Creative Commons Attribution 4.0 License.

\section{Overland flow characterization under no-tillage in Southern Brazil}

\author{
Fabio José Andres Schneider ${ }^{1}$, Jean Paolo Gomes Minella ${ }^{1}$, Ana Lucia Londero ${ }^{2}$, Dinis Deuschle ${ }^{1}$, \\ Alice Prestes Bisso Dambroz ${ }^{1}$, Gustavo Henrique Merten ${ }^{3}$, and Olivier Evrard ${ }^{4}$ \\ ${ }^{1}$ Federal University of Santa Maria, Department of Soil, Brazil (jminella@gmail.com) \\ ${ }^{2}$ Agronomic Institute of Paraná, Brazil \\ ${ }^{3}$ University of Minnesota Duluth, Department of Civil Engineering, United States \\ ${ }^{4}$ Université Paris-Saclay, Laboratoire des Sciences du Climat et de l'Environnement (LSCE), France
}

No-till is considered an efficient soil and water conservation practice when accompanied by crop species diversification and overland flow control. However, the last twenty years in south Brazil, farmers under no-till abandoned crop diversification and others soil conservation practice. As a consequence, severe erosion process have been observed caused by overland flow. The overland flow has been intensified due to a combination of problems such as soil compaction and poor surface residues. Understanding the formation and propagation of overland flow when the no-till is submitted to different agronomic conditions and practices mechanics as terraces is crucial for the improvement of conservationist agriculture, since many associated problems have caused environmental and economic damage. Unfortunately, there is currently a lack of information about the surface runoff processes occurring under no-till, which is essential to define the best water management practices. The objective of this study was to determine parameters related to surface runoff under different conditions of no-till, specifically regarding the amount of biomass, mechanical scarification and presence of terraces. The study was performed at the hillslope scale in southern Brazil characterized by a deep, clay and weathered soil under no-till. Two zero order catchments (2.4ha) and four hillslopes runoff plots $(0.5 \mathrm{ha})$ were monitored during natural rainfall from 2014 to 2018. These catchments and runoff plots are paired and have different soil management to test their respective effects on infiltration and overland flow. In the catchments the presence of terraces was evaluated and in the runoff plot the amount of biomass and mechanical scarification was evaluated. Precipitation was measured with pluviographs and overland flow was carried out automatically on $\mathrm{H}$ flumes with sensor pressures. A set of 63 rainfallrunoff events were monitored at the outlet of zero order catchments $(2,4 \mathrm{ha})$ and 27 events were observed in the along the runoff plots (0.5ha). From these events, we derived information reflecting the influence of mechanical scarification, of terraces and of biomass. The variables derived for each management mode were: Runoff coefficient (RC), Peak water discharge (PWD), Curve Number (CN), Sediment Yield (SY) and apparent infiltration (Al). In catchments, the main results demonstrate $a$, influence of terraces on overland flow control, where the reduction reached $50 \%$ for $\mathrm{RC}, 12 \%$ for $\mathrm{CN}$, and $60 \%$ for PWD, and $70 \%$ for SSC. Furthermore, infiltration increased by $11 \%$. In runoff plots, the influence of increasing biomass with scarification the reduction was $16 \%$ for RC, $5 \%$ for CN, 6.3\% for PWD and 6\% for SSC. In runoff plots, the influence 
of increasing biomass without scarification the reduction was $27 \%$ for RC, $5.4 \%$ for $\mathrm{CN}, 13 \%$ for PWD and $81 \%$ for SSC. The results demonstrated that the presence of terraces mitigated the overland flow; however, despite the positive effect of amount of biomass and mechanical scarification, its performance is of less impact. This set of original results will provide the data to quantify the impact of different management conditions and will assist the local managers in the planning of conservationist practices adapted to the conditions observed in Southern Brazil. 